\title{
PerCursos
}

\section{Contribuições de Caio Prado Júnior, Celso Furtado e Florestan Fernandes para pensarmos o desenvolvimento capitalista no século XXI}

\begin{abstract}
Resumo
Com diferentes nuances, o uso do termo desenvolvimento tem sido frequentemente associado às ações do Estado que visam mitigar as desigualdades, sejam elas regionais, sociais, econômicas etc. Dessa forma, no contexto do século XXI, parece-nos pertinente voltar a esse debate, tendo em consideração autores brasileiros que foram e continuam sendo fundamentais para refletirmos sobre o desenvolvimento: Caio Prado Júnior, Celso Furtado e Florestan Fernandes. Objetivamos identificar como o conceito de desenvolvimento está presente nestes intelectuais, refletindo sobre como suas contribuições nos valem para pensarmos o desenvolvimento capitalista atualmente, em especial na América Latina.
\end{abstract}

Palavras-chave: Desenvolvimento. Subdesenvolvimento. Capitalismo dependente. Teoria crítica.
Leônidas de Santana Marques

Licenciado em Geografia pela

Universidade Estadual de Feira de

Santana - UEFS. Mestre em

Geografia pela Universidade Federal de Sergipe - UFS. Doutorando em

Geografia Humana pela Universidade de São Paulo - USP.

Professor da Univ. Federal de Alagoas - UFAL.

Brasil

leonidas.marques@delmiro.ufal.br

\footnotetext{
Para citar este artigo:

MARQUES, Leônidas de Santana. Contribuições de Caio Prado Júnior, Celso Furtado e Florestan Fernandes para pensarmos o desenvolvimento capitalista no século XXI. Revista PerCursos, Florianópolis, v. 21, n.46, p. 272 - 300 , maio/ago. 2020.
} 


\title{
Contributions of Caio Prado Júnior, Celso Furtado and Florestan Fernandes to understand the capitalist development in the 21st century
}

\begin{abstract}
With different nuances, the term development has often been associated with State actions aimed at mitigating inequalities, be they regional, social, economic, etc. Thus, in the context of the 21st century, it seems pertinent to return to this debate, considering Brazilian authors who were and continue to be fundamental to reflect on development: Caio Prado Júnior, Celso Furtado, and Florestan Fernandes. We aim to identify how the concept of development is present in these intellectuals, reflecting on how their contributions are worth us to think about capitalist development today, especially in Latin America.
\end{abstract}

Keywords: Development. Underdevelopment. Dependent capitalism. Critical theory. 


\section{Introdução'}

A proposta deste texto é dialogar com um conceito que nos parece central para pensarmos a atualidade: desenvolvimento. Dada sua vaguidão, é necessário precisar de que desenvolvimento estamos tratando, qual seja, o das relações capitalistas de um modo geral, mas em especial no contexto de uma economia capitalista como o Brasil.

Mas qual o porquê de debater sobre o desenvolvimento? Seria um debate novo? Claro que não, muito pelo contrário! Justamente a partir de textos dos meados do século XX é que queremos desenvolver esta análise. Contudo, a presença desse debate há algumas décadas não justifica a sua não problematização. De tempos em tempos, a questão do desenvolvimento aparece com maior ou menor força nos ambientes acadêmicos e no teor das políticas públicas, em diferentes escalas. Chegou-se a afirmar, inclusive, que alguns países da América Latina estariam, nos primeiros anos do século XXI, vivenciado uma onda (neo)desenvolvimentista.

O objetivo geral deste trabalho é identificar como o conceito de desenvolvimento está presente em alguns dos textos de Caio Prado Júnior, Celso Furtado e Florestan Fernandes, refletindo sobre como estas contribuições nos valem para pensarmos o desenvolvimento das relações capitalistas atualmente. Com isso, não pretendemos esgotar todo o debate conceitual relacionado a esse termo em relação a outros autores contemporâneos a estes, tampouco desconsideramos a possibilidade de aprofundar essa reflexão com mais textos dos três autores selecionados. Nosso propósito se inscreve num indicativo de que esse importante debate crítico se coloca de modo intenso e qualificado ainda nos anos de 1940 no Brasil e os três intelectuais foram pioneiros nessas questões, não somente nacional como internacionalmente.

A título de exemplificação, podemos mencionar as reflexões trazidas por Peter Evans (1980) ao discutir o conceito de "tríplice aliança” para pensar o capitalismo dependente no Brasil. Na leitura empreendida por esse autor, estabelece-se no país uma aliança entre três segmentos: o capital internacional por meio das multinacionais, o

\footnotetext{
$1 \mathrm{O}$ autor agradece ao professor Alexandre de Freitas Barbosa, do Instituto de Estudos Brasileiros da Universidade de São Paulo, pelas contribuições e indicações ao longo da construção desse texto e por encorajar a publicação.
} 
capital nacional e o Estado nacional. Essas relações desenvolvem uma dependência estrutural mediada por uma unidade transnacional das elites. Assim, ao discutir sobre o conceito de desenvolvimento, o autor coloca que

O desenvolvimento dependente é um caso especial de dependência, caracterizado pela associação ou aliança do capital internacional e nacional. O Estado também participa da aliança como um sócio ativo, e a resultante tríplice aliança é um fator fundamental no aparecimento do desenvolvimento dependente. (EVANS, 1980, p. 42)

Com essa discussão, o autor traz interessantes questões para pensarmos o desenvolvimento das relações capitalistas no Brasil. Mas o que queremos ressaltar neste artigo são alguns dos referenciais desse livro, originalmente publicado em 1979 nos Estados Unidos. Autores brasileiros como Caio Prado Júnior, Celso Furtado e Florestan Fernandes são arrolados ao longo do texto, sendo centrais para a análise feita por Evans. Ou seja, há uma produção pioneira no Brasil sobre a questão do desenvolvimento do capitalismo, que ajuda não somente a entender o nosso país, mas toda uma série de relações que se estabelecem globalmente.

Além dessa introdução, o artigo está organizado em outras quatro partes. Na primeira, abordamos dois livros de Caio Prado Júnior: "História econômica do Brasil" $(1945)^{2}$ e "História e desenvolvimento" (1968). A partir dessas obras, debatemos o passado colonial na conformação do desenvolvimento brasileiro e como isso se reflete em uma compreensão específica de economia colonial no presente. Em seguida, abordamos duas obras de Celso Furtado: “Desenvolvimento e subdesenvolvimento" (1961) e “O mito do desenvolvimento econômico" (1974). Com esse autor, discutimos como aparecem de forma mais sistemática os conceitos de desenvolvimento e subdesenvolvimento, bem como estes se associam a uma leitura mais global de divisão internacional do trabalho. A terceira parte é referente a Florestan Fernandes, com as seguintes publicações: "Sociedade de classes e subdesenvolvimento" (1968), “A revolução burguesa no Brasil: ensaio de interpretação sociológica" (1975) e "Em busca do

\footnotetext{
${ }^{2}$ Neste parágrafo, os anos apresentados são referentes às primeiras edições das obras e não às edições a que tivemos acesso.
} 
socialismo: últimos escritos \& outros textos" (coletânea com textos dos anos 1970). Assim, debatemos como o conceito de capitalismo dependente ajuda no rompimento com uma leitura linear de desenvolvimento, dialogando também com o caráter desigual e combinado do desenvolvimento. Por fim, apresentamos as considerações finais como uma tentativa de diálogo entre questões que atravessam os três autores, tentando apontar algumas contribuições de suas obras para pensarmos o desenvolvimento do capitalismo no Brasil na atualidade.

Antes de debatermos diretamente as contribuições de cada um dos autores, uma ressalva é necessária 3 . Embora existam algumas importantes convergências, Caio Prado Júnior, Celso Furtado e Florestan Fernandes não apresentam abordagens concordantes em todo o tempo, muito pelo contrário. A formação intelectual e a experiência acadêmico-política de cada um foram constituindo uma visão sui generis sobre o desenvolvimento das relações capitalistas no Brasil. Contudo, nosso foco aqui vai no sentido de evidenciar as contribuições de cada autor na trilha de uma tradição crítica brasileira à leitura sobre o desenvolvimento capitalista, ressaltando o pioneirismo e ineditismo dos seus argumentos.

Essa evidenciação, por um lado, serve como fundamento para pensarmos e repensarmos o que de fato é o desenvolvimento das relações capitalistas num contexto de burguesia dependente e franco processo de reprimarização da economia nacional no Brasil do século XXI. Por outro lado, ressalvamos que este texto não deve ser lido como uma apologia acrítica das obras dos três autores que nos servem de base. Os próprios intelectuais mencionados apresentam uma produção acadêmica dinâmica, muitas vezes revendo conceitos e abordagens anteriores. Caio Prado Júnior, principalmente em sua relação direta com o Partido Comunista Brasileiro (PCB), reflete sobre o desenvolvimento das relações capitalistas no Brasil dialogando com demandas que eram próprias das teses e disputas internas à organização partidária. Os debates sobre a ausência de um período feudal no país ou o caráter nacional (ou não) da burguesia brasileira vão nesse sentido. Por sua vez, Celso Furtado apresenta um movimento muito interessante quanto ao

\footnotetext{
${ }^{3}$ Somos gratos aos colegas avaliadores pela leitura crítica do texto que levou à elaboração destes últimos parágrafos da introdução, bem como a alterações substanciais ao longo do artigo.
} 
debate sobre o desenvolvimento econômico, principalmente derivado de suas experiências em órgãos estatais, a exemplo da Comissão Econômica para a América Latina e o Caribe (CEPAL). Em alguns textos, podemos identificar um autor que acredita profundamente nas políticas de desenvolvimento como motor de superação de desigualdades; em outros, temos um Furtado mais descrente, mais voltado para uma compreensão histórica do desenvolvimento contraditório do capitalismo, que é justamente a produção intelectual que frisamos aqui. Já Florestan Fernandes apresenta nuances em sua abordagem que dialogam com várias tradições filosóficas e sociológicas que atravessaram sua carreira, tais como sua participação no movimento trotskista no início da vida, os diálogos que estabeleceu com a abordagem weberiana no começo da trajetória acadêmica, e o seu aprofundamento nos fundamentos marxianos com a maturidade.

\section{Caio Prado Júnior: a economia colonial como passado-presente no} desenvolvimento brasileiro

Do ponto de vista analítico, as diferentes produções de Caio Prado Júnior foram responsáveis por uma importante construção intelectual acerca da compreensão sobre o desenvolvimento das relações capitalistas no território brasileiro. Além das suas importantes inovações conceituais, o autor também se destaca de forma considerável por conta do período histórico em que escreve. Uma das obras aqui considerada, “História econômica do Brasil”, teve sua primeira edição em 1945, indicando o pioneirismo de Caio Prado Júnior na produção intelectual do Brasil ainda na primeira metade do século XX. Destarte, importa-nos considerar quais conceitos fundantes da produção desse autor são importantes para interpretarmos o desenvolvimento do capitalismo no Brasil, e para tanto partimos de duas obras: além da já citada, consideramos “História e desenvolvimento”, que teve sua primeira edição em 1968.

Um importante par conceitual que é trazido por Prado Júnior (1974) é: economia colonial e economia nacional. O segundo conceito indica um perfil de nação que se organiza em função das suas próprias necessidades; assim, as economias nacionais 
apresentam dinâmicas endógenas que determinariam seu modus operandi. Por outro lado, as economias coloniais apresentam uma dependência que lhe é própria e característica e que por isso determina a sua organização a partir de uma forte presença de interesses que estão além das fronteiras territoriais. Assim, o Brasil é compreendido como uma economia de razão colonial e essa forte presença de interesses internacionais associa-se principalmente à presença do capital financeiro (principalmente inglês no início do século XX, mas não somente) na nossa economia. Nos termos de Caio Prado Júnior, estaríamos diante de uma economia, de certo modo, limitada, que em seu desenvolvimento tropeça sequencialmente em um passado colonial.

\begin{abstract}
No curso, contudo, desse processo de transformação, esta esbarra no obstáculo dos remanescentes do velho sistema colonial que the embaraçam 0 prosseguimento e limitam as perspectivas. Resulta aquele obstáculo, fundamentalmente, [...] do acanhado mercado consumidor interno e sua defeituosa estrutura - herança ainda, em última instância, daquele passado colonial -, mercado esse que no regime vigorante de livre iniciativa privada que se estimula unicamente pelo maior interesse financeiro e maximização do lucro comercial, não oferece os impulsos necessários para a promoção das atividades econômicas em proporções e condições que assegurem um suficiente ritmo de crescimento do mesmo mercado. (PRADO JÚNIOR, 1989, p. 124)
\end{abstract}

Assim, o passado colonial presente na economia colonial brasileira é uma espécie de passado-presente, ou mesmo um passivo colonial que determina como se estabelecem e desenvolvem-se as relações capitalistas no Brasil. Esse argumento pode ser compreendido através de dois importantes momentos do desenvolvimento econômico brasileiro: as políticas de valorização da lavoura cafeeira e o processo de industrialização.

Em relação ao primeiro exemplo, Prado Júnior (1974) argumenta como a evolução agrícola derivada da política da lavoura cafeeira teve a participação explícita do capital financeiro internacional através da mediação do Estado brasileiro. Do ponto de vista político, o final do século XIX é marcado pela transição do Império para a República. Contudo, objetivamente, essa transição pouco significou enquanto política econômica para a lavoura cafeeira, que encontra no contexto republicano a continuidade e o 
aprofundamento da sua valorização. Nesse sentido, a presença do capital inglês, principalmente, incentivou a produção agrícola, mas também toda uma infraestrutura de circulação e escoamento da produção.

Ainda assim, mesmo com poucas rupturas políticas no cenário de valorização da lavoura cafeeira, é importante pontuar as importantes mudanças relacionadas ao perfil da força de trabalho (PRADO JÚNIOR, 1974). A transição do trabalho escravo para o trabalho livre ao longo do século XIX (com desdobramentos para o século XX) foi fundamental para o desenvolvimento das relações capitalistas no Brasil, isso levando em conta que essa transição se dá dialeticamente, transformando a sociedade como um todo. A “população livre, mas pobre, não encontrava lugar algum naquele sistema que se reduzia ao binômio 'senhor e escravo' [...]", sendo nesse processo que identificamos a “origem do proletariado industrial brasileiro, o que explicará no futuro muito das suas características e da sua evolução" (PRADO JÚNIOR, 1974, p. 198).

Além da presença do capital internacional na política de valorização da lavoura cafeeira, o autor constrói sua argumentação abordando o processo de industrialização brasileiro. O principal fenômeno analisado para esse momento do desenvolvimento econômico brasileiro é a presença substancial das indústrias subsidiárias, que são empresas que se instituem diretamente a partir de uma associação entre capitais locais e capitais estrangeiros, com determinação destes últimos.

Os capitais e empreendimentos internacionais se prevalecerão largamente dessa avantajada situação que desfrutam relativamente ao Brasil. [...] o núcleo verdadeiramente dinâmico da indústria brasileira se constituirá em nada mais que uma constelação de filiais de empresas internacionais em cuja órbita girará quase tudo que a nossa indústria conta de mais expressivo. [...] verifica-se desde logo a estreita relação de dependência que o predomínio de empreendimentos internacionais na indústria brasileira determina entre os processos de industrialização e as exportações brasileiras. (PRADO JÚNIOR, 1989, p. 126-127)

Desenvolvendo esse argumento, o autor identifica que esse perfil subsidiário do nosso processo de industrialização é um desdobramento do sistema colonial, ou melhor, do passivo colonial que se torna passado-presente no desenvolvimento das relações 
capitalistas no Brasil. Assim, a industrialização no nosso país tem como marca uma limitação estrutural que são os próprios limites de uma economia colonial como a brasileira. Impulsos descontínuos e desordenados tendem a ser a regra de uma indústria que é determinada mais por interesses da conjuntura financeira internacional do que por interesses internos às nossas fronteiras. Quando consideramos a realidade do Brasil no século XXI, ainda que passadas algumas décadas da formulação original do autor, vemos como a questão da industrialização nacional ainda é um importante ponto de debate. Em tempos de pandemia do Covid-19, por exemplo, fica ainda mais evidente o quão determinado por interesses exógenos é o processo de industrialização, incluindo o suprimento de equipamentos médicos e hospitalares.

Tanto a argumentação sobre as políticas de valorização do café como a referente ao processo de industrialização são dois importantes pilares para a leitura de Caio Prado Júnior sobre o desenvolvimento das relações capitalistas dependentes no Brasil. Com essas duas argumentações, o autor considera como se estabelece a crescente participação do capital internacional em nossa economia, e como os interesses desses capitais estrangeiros determinam e limitam o que poderia ser o desenvolvimento de uma economia de razão nacional (em oposição à razão colonial). Em termos de periodização histórica, o século XIX é compreendido como central para a elucidação das especificidades do desenvolvimento das relações capitalistas no Brasil, como ressaltado no fragmento a seguir.

\footnotetext{
O Brasil inaugurava-se num novo plano que desconhecera no passado, e nascia para a vida moderna de atividades financeiras. Um incipiente capitalismo dava aqui seus primeiros e modestos passos. A incorporação das primeiras companhias e sociedades, com seu ritmo acelerado e apesar dos exageros e certo artificialismo, assinala assim mesmo o início de um processo de concentração de capitais que, embora ainda acanhado, representa ponto de partida para uma fase inteiramente nova. (PRADO JÚNIOR, 1974, p. 193)
}

Assim, o século XIX pode ser compreendido como um período-chave para entendermos a dinâmica do desenvolvimento das relações capitalistas no Brasil, mesmo reconhecendo que muitos processos novos se evidenciam apenas no século seguinte. 
Concluindo essa reflexão acerca das contribuições de Caio Prado Júnior, ainda vale mencionar o debate sobre o caráter imperial do capitalismo global e como a reflexão soma-se à leitura que o autor faz sobre a economia de razão colonial que temos no Brasil.

[O imperialismo] forma um sistema amplo e geral de organização econômica do mundo, em que tais inversões não constituem mais que um dos elos da grande corrente que envolve o universo e mantém ligados todos os povos numa única estrutura que tem por centro diretor os grupos controladores do capital financeiro internacional. Tais grupos são este punhado de gigantescos trustes que imperam respectivamente nos diferentes setores da economia contemporânea, e estendem também para o Brasil seus tentáculos absorventes. $\mathrm{O}$ que não exclui naturalmente as fricções e choques entre eles. Choques que tomam um caráter nacional porque, embora internacionais por essência, apelam nas lutas que têm de sustentar para o poder político de um ou de outra nação soberana que se põe a seu serviço. Identificam-se assim com nações e nacionalidades, arvoram uma bandeira, mas efetivamente seu caráter é internacional, e esta bandeira não é mais fachada atrás da qual se abrigam. (PRADO JÚNIOR, 1974, p. 277-278)

Com essa leitura sobre o imperialismo, Caio Prado Júnior identifica como o caráter colonial do desenvolvimento das relações capitalistas no Brasil não é algo isolado. Em outras passagens, ele também indica que o próprio perfil de economia colonial não é algo exclusivo do Brasil. Mas, para nós, importa ressaltar como já está presente, no autor, uma leitura articulada do desenvolvimento capitalista, que aparece a partir do conceito de imperialismo ao final de "História econômica do Brasil". Junto com o uso de outros termos, como “dependente" e "periférico", identificamos a possibilidade de traçar alguns diálogos do autor com os demais que discutiremos a seguir.

\section{Celso Furtado: os limites do desenvolvimento na busca por precisão} conceitual

Diferente de Caio Prado Júnior, Celso Furtado teve em diferentes obras a preocupação direta com os conceitos de desenvolvimento e subdesenvolvimento. Principalmente se considerarmos uma leitura que leva em conta a necessidade de uma intervenção do Estado como promotor da superação das desigualdades nacionais, a 
preocupação de Celso Furtado é salutar no sentido de pensar a complexidade dos desafios que tínhamos pela frente à luz de uma teorização que não se resume ao interior dos limites nacionais. Essa ponderação, contudo, sempre considerou que os aspectos estruturantes dos processos históricos de cada nação são cruciais para entendermos as especificidades de cada território, desde que estejam amparados em um robusto quadro analítico mundial. Para além desses pontos, também destacamos o pioneirismo de Celso Furtado; “Desenvolvimento e subdesenvolvimento" foi escrito em 1961, enquanto "O mito do desenvolvimento econômico" foi escrito em 1974.

Em nossa compreensão, um primeiro plano de análise da crítica que o autor estabelece com relação ao conceito de desenvolvimento é em relação à necessidade de considerarmos a dimensão histórica associada a qualquer processo econômico (FURTADO, 1961). Com isso, Celso Furtado se coloca contra uma perspectiva linear de análise do desenvolvimento econômico, muito em voga na segunda metade do século XX. Assim, ele refuta uma leitura que considere que existiriam etapas a serem seguidas para o desenvolvimento, ou melhor, para a superação da condição de subdesenvolvimento. Há uma nítida articulação entre desenvolvimento e subdesenvolvimento, e a universalização do modelo de desenvolvimento identificado em países como Estados Unidos ou Reino Unido é algo impraticável. Assim, ele critica que "pelo menos noventa por cento do que aí encontramos se funde na ideia, que se dá por evidente, segundo a qual o desenvolvimento econômico, tal qual vem sendo praticado pelos países que lideraram a revolução industrial, pode ser universalizado" (FURTADO, 1974, p. 16). Essa leitura linear, que nega a realidade histórica como complexa, não passa de um mito criado em torno do progresso.

Argumentando nesse sentido, Celso Furtado se vale de uma análise dos processos históricos que levaram às condições de desenvolvimento de determinados países, em detrimento dos demais. Os fatos determinantes que se estabeleceram, por exemplo, na experiência inglesa, são cruciais para esta compreensão: um intenso desenvolvimento comercial, seguido do respectivo desenvolvimento industrial, levou a uma importante concentração de capitais nesse país. Mas, para além de aspectos intranacionais, Furtado frisa que as fases do desenvolvimento industrial inglês levaram a um processo de redução 
no ritmo de crescimento e baixa da taxa de lucros e, assim, a "economia inglesa logrou evitar a eutanásia precoce lançando-se numa grande ofensiva internacional” (FURTADO, 1961, p. 167). Será principalmente a partir deste momento, em que o capitalismo "inglês" amplia seus horizontes para evitar a tendência à queda da taxa de lucros, que há uma ampliação desse modo específico de desenvolvimento das relações capitalistas para países como o Brasil. Esse contexto histórico cria condições não para um desenvolvimento pleno, mas para um desenvolvimento que depende e se vincula diretamente aos determinantes de além-mar, ou seja, para uma forma de subdesenvolvimento. Para nos aprofundarmos na definição conceitual desse termo, é salutar indicar que

[...] o subdesenvolvimento deve ser entendido como um processo, vale dizer, como um conjunto de forças em interação e capazes de reproduzir-se no tempo. Por seu intermédio, o capitalismo tem conseguido difundir-se em amplas áreas do mundo sem comprometer as estruturas sociais pré-existentes nessas áreas. 0 seu papel na construção do presente sistema capitalista mundial tem sido fundamental e seu dinamismo continua considerável: novas formas de economias subdesenvolvidas plenamente industrializadas e/ou orientadas para a exportação de manufaturas estão apenas emergindo. É mesmo possível que ele seja inerente ao sistema capitalista; isto é, que não possa haver capitalismo sem as relações assimétricas entre sub-sistemas econômicos e as formas de exploração social que estão na base do subdesenvolvimento. (FURTADO, 1974, p. 94)

Com esse fragmento, o autor estabelece importantes bases para compreendermos o que é o subdesenvolvimento: a) este é um processo, e não uma etapa; b) no (sub)desenvolvimento das relações capitalistas, não há uma desconsideração das estruturas sociais que ali já existem, muito pelo contrário; c) o capitalismo mundial, como o conhecemos, se estabeleceu a partir do subdesenvolvimento também, e não somente do desenvolvimento. Dessa forma, o subdesenvolvimento é "um processo histórico autônomo, e não uma etapa pela qual tenham, necessariamente, passado as economias que já alcançaram grau superior de desenvolvimento" (FURTADO, 1961, p. 173). 
O estabelecimento do subdesenvolvimento em uma nação vai sendo compreendido, então, a partir de uma perspectiva relacional em nível global; não como uma possível incompletude do desenvolvimento das relações capitalistas, mas como um grau de acumulação de capital nos processos produtivos. Com essa argumentação, Celso Furtado não somente desconstrói uma leitura etapista, como também é categórico em apontar que "as economias da periferia nunca serão desenvolvidas" (FURTADO, 1974, p. 75). Isso se explica por diferentes razões, que vão desde a não repetibilidade dos processos históricos, até as próprias limitações ambientais do meio físico, haja vista os padrões de produção e consumo estabelecidos nos países centrais. Aqui, sem sombra de dúvidas, temos um dos momentos mais críticos do autor frente ao debate sobre o desenvolvimento capitalista. Furtado revisará essa postura em obras posteriores, mas a ideia de enfatizarmos aqui essa argumentação vai mais no sentido de considerarmos os conceitos mobilizados pelo autor para chegar a essa reflexão, o que nos parece precioso na construção de uma crítica a uma ideologia neodesenvolvimentista no Brasil do século $\mathrm{XXI}$.

A relação-chave considerada por Furtado para entendermos como se conectam os países periféricos e os países centrais é o recorrente intercâmbio desfavorável entre as economias nacionais. Nesse sentido, mesmo com distintos graus de inserção, as economias subdesenvolvidas estabelecem intercâmbios desfavoráveis que estruturalmente agudizam a desigualdade em favor dos países centrais. Assim, o desenvolvimento desses países levou a uma crescente interconexão global entre as nações em seus diferentes padrões econômicos nacionais. Através dessa interconexão, “estava aberto o caminho para a introdução de todas as formas de intercâmbio desigual', que historicamente caracterizam as relações entre o centro e a periferia do sistema capitalista" (FURTADO, 1974, p. 85).

Esse intercâmbio desigual, considerado pelo autor, se organiza, notadamente, a partir do uso e aplicação do excedente. $\mathrm{O}$ incremento progressivo da produtividade nos diferentes países vai implicando numa respectiva produção de excedente; nessa direção, a forma como este vai sendo utilizado em cada contexto nacional vai evidenciando uma linha divisória entre o desenvolvimento e o subdesenvolvimento. Do ponto de vista da 
produção do espaço em escala mundial, o processo se desdobra em configurações geográficas da divisão internacional do trabalho. Assim, alguns países vão se especializando na produção e exportação de determinados itens, como no exemplo típico dos produtos agrícolas e nas commodities de um modo geral.

A nossa hipótese central é a seguinte: o ponto de origem do subdesenvolvimento são os aumentos de produtividade do trabalho engendrados pela simples realocação de recursos visando a obter vantagens comparativas estáticas no comércio internacional. O progresso técnico [...] e a correspondente aceleração no processo de acumulação [...] permitiram que em outras áreas crescesse significativamente a produtividade do trabalho, como fruto da especialização geográfica. [...] o excedente adicional, assim criado, pode permanecer no exterior em sua quase totalidade, o que constituía a situação típica das economias coloniais. Nos casos em que esse excedente foi parcialmente apropriado do interior, seu principal destino constituiu em financiar uma rápida diversificação dos hábitos de consumo das classes dirigentes, mediante a importação de novos artigos. Este uso particular do excedente adicional deu origem às formações sociais atualmente identificadas como economias subdesenvolvidas. (FURTADO, 1974, p. 78)

Diferentemente de muitos que refletiam sobre os rumos do (sub)desenvolvimento brasileiro nos primeiros anos da segunda metade do século XX, Furtado não identificava que o processo de intercâmbio desigual pudesse ser revertido por um processo simples de transferência de tecnologia via industrialização. O papel que a Revolução Industrial teve, por exemplo, na consolidação e no desenvolvimento das relações capitalistas no contexto inglês não pode ser simplesmente replicado para a realidade brasileira. Se, no primeiro caso, a industrialização apresenta um papel orientador de formação de um sistema econômico nacional, no caso brasileiro se apresenta apenas como um desdobramento do sistema econômico internacional. Desse modo, temos uma industrialização dependente, que se reproduz na periferia mantendo seu centro de comando nos países centrais. Assim, o "mesmo" processo de industrialização que, nos países centrais, é responsável por um ciclo virtuoso de repartição da renda, se apresenta como um ciclo vicioso nos países periféricos, provocando crescente concentração. Aqui, a título de comparação, vemos uma substancial diferença entre as perspectivas de Caio Prado Júnior e Celso Furtado. Enquanto no primeiro temos uma leitura da industrialização 
que não se completa em sua plenitude, no segundo temos um processo que se realiza, porém, retroalimentando a condição de país subdesenvolvido.

Por fim, queremos evidenciar outros dois importantes argumentos discutidos por Celso Furtado na sua abordagem sobre o desenvolvimento das relações capitalistas: o caráter combinado do subdesenvolvimento e como a relação desenvolvimentosubdesenvolvimento se estabelece globalmente. Embora essas considerações já tenham sido colocadas ocasionalmente antes, apontaremos alguns pontos a mais no debate.

No processo de desenvolvimento das relações capitalistas em países como o Brasil, as estruturas arcaicas não são eliminadas, na leitura de Celso Furtado. Muito pelo contrário, há uma hibridização entre o arcaico e as novas relações, gerando nuances completamente distintas, o que ajuda a compreender também a importância do reconhecimento dos aspectos nacionais nesse argumento. Dessa forma, o "dinamismo da economia capitalista resulta, em última instância, do papel que nela desempenha a classe em que um núcleo capitalista passava a coexistir, pacificamente, com uma estrutura arcaica" (FURTADO, 1961, p. 176-177). Aprofundando o argumento, o autor indica que o subdesenvolvimento tem raízes na complexa relação que se estabelece entre o processo interno de exploração e o processo externo de dependência. E o crescimento econômico nessas circunstâncias apenas tende a agravar a condição de subdesenvolvimento (FURTADO, 1974).

Partindo de uma perspectiva escalar global, o autor desenvolve uma reflexão que dialoga com os conceitos de desenvolvimento e subdesenvolvimento e a própria organização do espaço mundial.

O advento de um núcleo industrial, na Europa do século XVIII, provocou uma ruptura na economia mundial da época e passou a condicionar o desenvolvimento econômico subsequente em quase todas as regiões da terra. A ação desse poderoso núcleo dinâmico passou a exercer-se em três direções distintas. A primeira marca a linha do desenvolvimento, dentro da própria Europa ocidental, no quadro das divisões políticas que se haviam cristalizado na etapa mercantilista anterior. [...] A segunda linha de desenvolvimento da economia industrial europeia consistiu num deslocamento para além de suas fronteiras, onde quer que houvesse terras ainda desocupadas e de características similares às da própria Europa. [... ] A terceira linha de expansão da economia industrial foi em direção às regiões já ocupadas, algumas delas 
densamente povoadas, com seus sistemas econômicos seculares, de variados tipos, mas todos de natureza pré-capitalista. [... ] este tipo de economia dualista constitui, especificamente, o fenômeno do subdesenvolvimento contemporâneo. (FURTADO, 1961, p. 171-173)

Nesse processo de separação entre países centrais desenvolvidos e países periféricos subdesenvolvidos, o autor não estabelece somente uma distinção, mas também uma importante conexão entre eles. Como já colocado, há um substancial esquema de intercâmbios desiguais que fomenta e agudiza essa separação. Contudo, mais do que isso, consideramos importante ressaltar o caráter centralizado das decisões que se estabelecem globalmente. Assim, a aplicação ou não de dinheiro em um determinado negócio é definida essencialmente nos países centrais. E mais, pois "a grande empresa, ao organizar um sistema produtivo que se estende do centro à periferia, consegue, na realidade, incorporar à economia do centro os recursos de mão de obra barata da periferia" (FURTADO, 1974, p. 50). Dessa forma, como discutido em relação ao processo de industrialização, o desenvolvimento das relações capitalistas de produção contribui para ampliar o fosso entre as economias nacionais. Para analisar o fenômeno, Celso Furtado se vale reiteradamente do termo dependência. Embora não sejam equivalentes em todas as situações, subdesenvolvimento e dependência são dois conceitos que ajudam decididamente a compreender o quadro econômico brasileiro. Ainda assim, ponderamos que não será esse autor, mas Florestan Fernandes, que desenvolverá uma importante agenda de pesquisa sobre a relação entre desenvolvimento e dependência nas ciências humanas no Brasil.

\section{Florestan Fernandes: desenvolvimento e subdesenvolvimento no}

\section{capitalismo dependente}

Muitas das preocupações acerca do desenvolvimento das relações capitalistas no Brasil pontuadas por Caio Prado Júnior e Celso Furtado também foram do interesse de Florestan Fernandes. Por um lado, isso não quer dizer, contudo, que haja uma continuidade ou mesmo derivações de um autor para o outro. Como temos apontado 
desde o início, a leitura sobre o desenvolvimento das relações capitalistas no Brasil passa necessariamente pelas contribuições desses três autores. Por outro lado, ter em conta os três não significa transformá-los numa coisa só, haja vista que em muitos pontos esses intelectuais foram discordantes.

Ao discutir sobre os desdobramentos do capitalismo na Europa em relação ao Brasil, Florestan Fernandes também contribuiu com o debate sobre as especificidades da acumulação capitalista no país. Assim, ao passo que na Europa se desenvolveu um processo de acumulação estamental de capital que se conformou como uma fase do desenvolvimento econômico, no Brasil esse processo se transformou em um estado econômico permanente (FERNANDES, 2006). Nessa linha de argumentação, concordando com o que já foi colocado antes pelos outros intelectuais, é errônea a ideia do subdesenvolvimento como uma etapa circunstancial das economias nacionais latinoamericanas, sendo, portanto, uma condição própria de reprodução do capitalismo (em sua fase monopolista). Dessa forma, nega-se a uma leitura linear do desenvolvimento das relações capitalistas, se opondo a uma compreensão de um único padrão intrínseco ao capitalismo, universal e invariável. Essa condição diferencial dos países não desenvolvidos implica, inclusive, numa ressignificação do debate.

As 'questões do desenvolvimento' interessam aos países que possuem autonomia ou desfrutam algum grau de hegemonia dentro do mundo capitalista. Os demais países - não importa onde estejam: na Europa, na América Latina, na África ou na Ásia - devem preocupar-se não com essas questões, mas com os efeitos negativos de uma modernização controlada de fora, a qual sempre exige e acarreta algum crescimento econômico, e com as próprias possibilidades de uma revolução nacional através do socialismo. (FERNANDES, 1995, p. 139)

Assim, o autor rechaça os debates, ainda recorrentes no Brasil do século XXI, quanto a uma possível "salvação pelo desenvolvimento" ou mesmo "revolução pelo desenvolvimento". São discussões inócuas num contexto de desenvolvimento capitalista dependente. O que muitas vezes aparece enquanto discurso de uma "transição de amadurecimento na comensalidade" não passa de uma cortina que encobre a 
dependência estrutural do desenvolvimento capitalista em países como o Brasil (FERNANDES, 1995).

É justamente com esse debate, a questão da natureza dependente do capitalismo nos países periféricos, que Florestan Fernandes indica importantes avanços acerca da discussão sobre o desenvolvimento das relações capitalistas em territórios como o do Brasil. Podemos colocar esse argumento a partir da citação que segue:

\begin{abstract}
As economias nacionais que dispõem de auto-suficiência e de autonomia econômica contam com condições para se ajustarem ao mercado mundial em função de determinações racionais dos próprios interesses econômicos, podendo resguardar e fortalecer as tendências de concentração de poder e de monopolização das vantagens econômicas garantidas por sua posição autônoma (no plano nacional) e hegemônica (no plano internacional). As economias nacionais dependentes organizam-se basicamente em função de condições, oportunidades e limitações impostas pelo mercado mundial e, através dele, pelas economias nacionais a que se articulam em posição heteronômica. Em consequência, o seu próprio crescimento interno espalha, estrutural e dinamicamente, a natureza, a intensidade e a variação ou a flutuação dos interesses das economias nacionais a que se associam heteronomicamente. (FERNANDES, 2008, p. 38)
\end{abstract}

Com esse debate, o autor traz dois pares conceituais interessantes para pensarmos como acontece o desenvolvimento capitalista, na relação entre economias nacionais “autossuficientes" e “dependentes". As primeiras apresentam, no plano nacional, um desenvolvimento autônomo e, no plano internacional, um desenvolvimento hegemônico. As economias nacionais dependentes, por sua vez, apresentam um desenvolvimento que se dá heteronomicamente. Essa relação, contudo, não deve desconsiderar a determinação fundamental do desenvolvimento dependente; assim, a partir de dentro, essa forma de subdesenvolvimento é produzida e mantida, ainda que seja a partir de fora que ela seja condicionada e regulada. Ou seja, a consideração das escalas nacional e internacional deve levar em conta que é na mediação entre estes que se dá o capitalismo dependente. Nessa direção, salientando dialeticamente o argumento de Fernandes, identificamos a relação entre "países desenvolvidos" e "países subdesenvolvidos" como uma interconexão da qual deriva propriamente a dependência dos segundos em relação aos primeiros. 
Ao longo do tempo, com a reafirmação do caráter dependente dessa forma de (sub)desenvolvimento, há uma intensificação da dependência. Dito de outro modo, as diferentes medidas estatais pensadas e implementadas, quando não consideram romper com as especificidades da dependência, apenas reforçam a condição estrutural.

[...] a ordem econômica assim constituída adapta-se, estrutural, funcional e evolutivamente, ao padrão de equilíbrio dinâmico de uma economia capitalista articulada e dependente. Ela se acomoda à neutralização de vários fatores, inevitavelmente excluídos dos mecanismos de mercado capitalista, e ao se expandir, generalizando-se e se intensificando, tende a concentrar as transformações de maior significado no próprio setor moderno. Por conseguinte, em vez de concorrer para o aparecimento de uma economia capitalista auto-suficiente, essa ordem econômica induz a monopolização do crescimento pelo setor moderno e aumenta constantemente a distância existente entre ele e o setor arcaico. (FERNANDES, 2008, p. 64)

Essa expansão/generalização/intensificação se desdobra em um acirramento da desigualdade entre setores arcaicos e setores modernos das relações capitalistas. Nesse processo, é possível presumir uma tendência à instabilidade maior nos países (sub)desenvolvidos em relação aos demais, aquilo que o autor chama de "insegurança crônica". Tendo em conta as fragilidades das democracias instituídas nesses países, podemos pensar, inclusive, como essa insegurança crônica se traduz nas frequentes ingerências externas, diretas ou indiretas, nos processos políticos e econômicos dessas nações.

As evidências de uma economia nacional de caráter dependente aparecem em todo o processo de formação territorial do Brasil. Em “A revolução burguesa no Brasil”, Florestan Fernandes aborda a questão com muito relevo quando considera a estruturação do Estado nacional que surge no século XIX. As contradições presentes no contexto, a partir dos diversos interesses conservadores e liberais que atravessaram o Império, apontam para um conjunto de características que ponderam os limites da autonomização política que se estabelece a partir desse período. Fernandes (2006), ao pensar sobre essa autonomização, indica que esta deve ser a base para entendermos 
todos os desenvolvimentos ulteriores da sociedade brasileira. Assim, compreende-se que duas linhas existem para a análise do desenvolvimento do capitalismo no Brasil.

\begin{abstract}
Uma, que se origina com a própria colonização e se prende aos desígnios econômicos do capitalismo comercial. Ela primeiro projetou o 'senhor agrário' numa posição marginal e mais tarde o converteu em sujeito de transações econômicas, cujos agentes verdadeiros ficavam no exterior. [...] a outra linha originou-se da autonomização política e das tendências históricas que ela engendrou, de criação de uma economia, de um estado e de uma sociedade nacionais, sob modelos institucionais tomados da civilização ocidental moderno. (FERNANDES, 2006, p. 104-105)
\end{abstract}

Essas duas linhas, contraditoriamente, são a base daquilo anteriormente citado como insegurança crônica, embora sejam também a condição fundamental de reprodução das relações capitalistas no Brasil. Essa especificidade de desenvolvimento, no caso nacional, acontece com duas importantes limitações: a) em nenhum momento apresenta-se o rompimento com a associação dependente em relação aos centros hegemônicos imperialistas; b) nunca se dá, integralmente, a desagregação do antigo regime e do respectivo poder colonial nas décadas que se seguem ao Império. Essas razões históricas nos ajudam a entender aquilo que Florestan Fernandes argumenta quanto à dependência não ser somente um processo que se dá de fora para dentro. Acontece uma dupla articulação: entre burguesia dependente nacional e imperialismo internacional no plano externo; e entre o arcaico e o moderno no plano interno. No século XXI, a título de exemplificação, essa articulação pode ser identificada nos mais diferentes setores da economia brasileira: agronegócio, construção civil, telecomunicações etc.

A transição de uma sociedade colonial para uma sociedade nacional, que vai se dando ao longo do século XIX, mas com reflexos até os dias atuais, é um processo crucial para a conformação das articulações presentes no desenvolvimento das relações capitalistas na Brasil. O caráter dependente daí derivado se apresenta tanto nas especificidades das articulações, como no desenho do Estado nacional que interessava a esse contexto social e econômico. 
Outro importante avanço conceitual colocado por Florestan Fernandes para pensarmos o desenvolvimento das relações capitalistas no Brasil é a questão do regime de classes presente numa sociedade com as especificidades que apresenta a nossa.

\begin{abstract}
O ponto central para a caracterização sociológica das classes sociais em sociedades subdesenvolvidas está, naturalmente, no modo pelo qual os processos de estratificação social se vinculam com a ordem econômica, criada pela existência de uma economia de mercado de bases capitalistas. Em regra, as descrições e as explicações sociológicas pressupõem um modelo ideal, que poderíamos designar como linear, do qual o protótipo é fornecido pelo capitalismo competitivo, na forma em que ele se constituiu em conexão com a revolução comercial e industrial na Inglaterra. No entanto, no momento em que uma sociedade subdesenvolvida consegue realizar as condições estruturais, funcionais e históricas, pressupostas em tal modelo, ela deixa de ser subdesenvolvida, concretizando em algum grau significativo o padrão de equilíbrio e de crescimento inerente ao capitalismo auto-suficiente e autônomo. Por isso, seria conveniente considerar-se as conexões entre os processos de estratificação social e a formação ou a diferenciação do mercado capitalista em diferentes modelos, anteriores a essa passagem do subcapitalismo e do capitalismo dependente para formas de capitalismo integrado. (FERNANDES, 2008, p. 33)
\end{abstract}

Com essa ponderação, o autor não só se opõe a uma leitura linear da história, como também aponta para a necessidade de compreensão para as realidades dos países subdesenvolvidos em suas especificidades quanto às diferentes possibilidade de estratificação social, ou melhor, quanto aos regimes de classe que se estabelecem. Com isso, Fernandes não aponta para uma flexibilização da teoria geral sobre as classes sociais no capitalismo, mas pondera a necessidade de entendermos que em diferentes contextos espaciais, as mesmas classes (frações de classe) apresentam arranjos distintos. Podemos ainda nos aprofundar mais nesse intento analítico e pensar como, diante das articulações estabelecidas no capitalismo dependente em níveis nacionais e internacionais, as frações da classe burguesa podem apresentar comportamentos convergentes ou divergentes de acordo com o seu grau de articulação com interesses que estabelecem para além das fronteiras nacionais.

Partindo dessa reflexão sobre o regime de classes diferenciando que temos no desenvolvimento das relações capitalistas no Brasil, Fernandes estabelece um diálogo muito recorrente entre os intelectuais da segunda metade do século XX: a questão da 
revolução burguesa no contexto nacional. Num primeiro plano, o autor considera a necessidade de considerarmos a especificidade da burguesia que se estabelece aqui e, para tanto, aponta para o conceito de modernização. Com este, argumenta que o que se deu no Brasil, inicialmente, foi uma transferência de normas, instituições e valores sociais (mais que padrão de cultura ou um padrão de integração da ordem social). Para além dos aspectos de ordem subjetiva, a formação da burguesia de uma sociedade capitalista subdesenvolvida é marcada por contingências econômicas relacionadas à sua sobrevivência frente ao modus operandi já estabelecido. Além disso, lidam com as demandas e imposições que são constituídas externamente.

[...] as burguesias do mundo capitalista subdesenvolvido são vítimas da estrutura e da organização da sociedade de classes em que vivem. Elas veem o capitalismo e suas exigências sociais, culturais e políticas do ângulo do capitalismo dependente. Ao fazer sua revolução, fazem-na na escala das realizações e ambições fomentadas pelo capitalismo dependente. Nenhuma outra classe social as contesta com probabilidades de êxito. De qualquer modo, condenam-se a protagonizarem a história como uma eterna façanha de dependência. Para que eles se ergam acima dessa medida, precisam ser negadas e arrostadas por outras classes. Enfim, precisam ser compelidas a pensar e a transformar o mundo de uma perspectiva universal. (FERNANDES, 2008, p. 93)

O debate sobre o papel da burguesia na sua revolução em relação ao Brasil oscila um pouco ao longo do pensamento desse autor. Não obstante, vale a pena evidenciar o posicionamento que ele delineia nos trabalhos a partir da década de 1970: a revolução burguesa ocorreu no Brasil, mas se estabeleceu a partir de uma busca pelo crescimento econômico rápido nas condições permanentes do capitalismo dependente (FERNANDES, 1995). Isso, contudo, não nos deve levar à interpretação de que no Brasil há uma burguesia débil. A sociedade (e o Estado) derivados da revolução burguesa no Brasil, ainda que distante de um caráter nacionalista-democrático, são extremamente articulados na reprodução e manutenção do caráter dependente do capitalismo. Essa “burguesia é a digna descendente da 'burguesia clássica' e é tão útil para a continuidade e o aperfeiçoamento do capitalismo quanto o foi aquela" (FERNANDES, 1995, p. 143). 
Aqui temos um importante diferencial entre os escritos de Caio Prado Júnior e Florestan Fernandes. Justamente quando consideramos o debate sobre o papel da burguesia brasileira e o processo de revolução capitalista no país, vemos como, a partir dos anos 1970, Florestan Fernandes apresenta uma leitura clara sobre a inviabilidade de considerarmos a espera da "nossa" revolução burguesa por um simples motivo: ela já teria ocorrido. Essa teorização se torna clara para o autor principalmente após o acirramento das contradições do regime ditatorial empresarial-militar brasileiro no final dos anos 1960. No caso de Caio Prado Júnior, essa conclusão não se apresenta. Muitos dos intelectuais orgânicos ao PCB, no intento de defender a construção de uma frente democrática ampla, argumentavam em favor do caráter nacionalista e progressista de uma fração da burguesia brasileira. Essa postura do partido somente será revista no final do século XX e o próprio Caio Prado Júnior falece antes disso, no início dos anos 1990.

Concluindo essas reflexões específicas sobre algumas das contribuições de Florestan Fernandes para pensarmos o desenvolvimento das relações capitalistas no contexto brasileiro, nos parece importante salientar um outro ponto muito recorrente nos escritos do autor: o caráter combinado do desenvolvimento desigual capitalista. A leitura sobre a questão do desenvolvimento desigual das relações capitalistas está presente em quase toda literatura de natureza crítica, incluindo os autores que discutimos anteriormente. Contudo, a questão do caráter combinado desse desenvolvimento desigual não é algo tão recorrente, seja pela consideração de que a combinação é imanente ao desenvolvimento desigual, seja pela desconsideração. Assim, a ênfase que encontramos nos trabalhos de Florestan Fernandes à combinação do arcaico com o moderno no desenvolvimento capitalista no Brasil não é algo gratuito e dialoga diretamente com seu percurso formativo no movimento trotskista ${ }^{4}$ na década de 1940 (FERNANDES, 1980). Partindo de uma compreensão do desenvolvimento desigual e

\footnotetext{
${ }^{4}$ Embora o debate sobre o desenvolvimento desigual esteja presente de diferentes modos em Marx, Engels e Lenin, será com Trotsky, e com o movimento trotskista de um modo geral, que esse processo se apresentará como uma nova síntese conceitual dialética: desenvolvimento desigual e combinado. Embora atualmente a teoria tenha um uso mais disseminado nas ciências humanas e sociais, é preciso ponderar sua limitada abrangência (assim como de toda a teoria marxista) no Brasil dos meados do século XX, por isso frisamos esse ponto no pensamento de Florestan Fernandes.
} 
combinado, ele é entendido considerando a necessidade das contradições no movimento dialético da formação territorial.

[...] estruturas econômicas em diferentes estágios de desenvolvimento não só podem ser combinadas organicamente e articuladas no sistema econômico global. O próprio padrão de equilíbrio deste sistema, como um todo, e sua capacidade de crescimento definem-se e são perseguidos por esses meios, sem os quais o esvaziamento histórico dos ciclos econômicos conduziria, fatalmente, da estagnação à decadência e desta à regressão econômica sistêmica. (FERNANDES, 2008, p. 61)

Interessante enxergar como o autor compreende a leitura do desenvolvimento desigual e combinado a partir de um capitalismo dependente como o caso brasileiro. Assim, estabelece-se um equilíbrio dinâmico na combinação entre o arcaico e o moderno, e esse equilíbrio se reproduz, não sem contradições, num contexto de articulação entre as frações de capitais em diferentes níveis e escalas. Ou seja, o arcaico se reproduz em mediação como o moderno no plano nacional, mas também a partir de relações imperialistas no plano internacional. Isso também pode ser pensado em relação ao moderno em sua mediação com o arcaico e com as relações imperialistas. Deriva daí um importante e complexo conjunto teórico analítico para pensarmos a relação entre os capitais no contexto de países subdesenvolvidos. Essas relações, que estruturam a formação territorial do Brasil, formam aquilo que o autor chama de "pacto sagrado" entre o arcaico e o moderno nos países subdesenvolvidos.

O capitalismo monopolista não eclode nas economias periféricas rompendo o seu próprio caminho, como uma força interna irreprimível que destrói estruturas econômicas arcaicas ou simplesmente obsoletas, dimensionando e reciclando o que deveria ser preservado e forjando suas próprias estruturas econômicas ou extra-econômicas. Vindo de fora, ele se superpõe, como o supermoderno ou o atual, ao que vinha de antes, ou seja, o "moderno", o "antigo" e o "arcaico", aos quais nem sempre pode destruir e, com frequência, precisa conservar. $O$ seu maior impacto construtivo consiste em cavar um nicho para si próprio, naquelas esferas das economias periféricas que são mais compatíveis com a transição, formando assim um exíguo espaço econômico, a partir do qual poderá crescer e quiçá irradiar-se para toda a economia, universalizando aos poucos os requisitos estruturais, funcionais e históricos inerentes ao seu próprio padrão de desenvolvimento capitalista. (FERNANDES, 2006, p. 314) 
O processo de desenvolvimento das relações capitalistas nos países periféricos, que tem como marca o subdesenvolvimento e a dependência estrutural frente aos países “desenvolvidos”, é assim atravessado por contradições que marcam toda a formação territorial de Estados nacionais, como no caso brasileiro. Nessa linha de argumento, Fernandes colabora com uma reflexão que critica a visão do contexto social e econômico que vivenciamos como uma etapa do desenvolvimento do capitalismo e que, por isso, o simples crescimento seria responsável por nos colocar em outro patamar na teia de articulações que se estabelece em nível global. Muito pelo contrário, o desafio da superação do subdesenvolvimento passa por questões de natureza política, que são compreendidas à luz dos processos históricos da nossa constituição a partir do século XIX. Processos estes que se dão tanto no nível nacional, mas também do ponto de vista das relações internacionais instituídas nesse momento.

Para além disso, a modernização desenvolvida no Brasil teve como marca processos que colocaram em segundo plano os princípios igualitários, democráticos e cívico-humanitários. Desse modo, o sentido da instituição de um processo civilizatório no país, via modernização capitalista, trouxe contradições entre aquilo que ocorreu nos contextos da Europa ocidental e o que se desdobrou, por exemplo, na América Latina. Contudo, longe de ser algo alienígena ou um erro de percurso, a partir do debate sobre o desenvolvimento desigual e combinado no contexto de Estados nacionais dependentes, Fernandes traz à tona a dialética do desenvolvimento, tanto no plano nacional, como no plano internacional.

\section{Considerações finais: um legado para pensarmos o desenvolvimento das}

\section{relações capitalistas no século XXI}

Atualmente, é muito corrente o debate sobre o desenvolvimento do Estado nacional brasileiro. Muitas leituras sobre esse conceito são apresentadas, algumas, inclusive, que são mera repetição de interpretações idealistas presentes há décadas na ciência. Acreditamos que um dos argumentos que pode apresentar uma convergência 
entre os escritos de Caio Prado Júnior, Celso Furtado e Florestan Fernandes é a oposição a qualquer forma de ideologia do desenvolvimento, enquanto falsa consciência. Interessante como velhos problemas relacionados à "questão do desenvolvimento brasileiro" reaparecem de modo intermitente no cenário das políticas públicas do Estado nacional. Muitos desses desafios não passam de carcomidos problemas que se transvestem de novos para, periodicamente, povoar o discurso de gestores e/ou intelectuais. Desenvolver o quê? Para quem? Por quê? Quem, no final das contas, ganha com o desenvolvimento? Essas questões estiveram latentes no pensamento desses três autores e devem permanecer vivas em qualquer análise que considere as especificidades do desenvolvimento das relações capitalistas na América Latina. E, de modo objetivo, essas questões moveram e movem muito do pensamento crítico, dentro e fora das universidades, no campo das ciências humanas e sociais.

De modo diferenciado, em cada um dos três intelectuais aqui focalizados, identificamos uma crítica à interpretação etapista e linear do desenvolvimento. Celso Furtado, por exemplo, critica duramente a ideia de uma inexorabilidade do desenvolvimento ou mesmo que a condição de país subdesenvolvido fosse uma necessidade prévia para que algum dia este venha a se tornar desenvolvido. A celeuma ainda deve ser alvo de muitos debates, ainda mais quando pensamos o que foi todo o debate sobre a formação dos BRICS e o discurso dos "países em desenvolvimento". Florestan Fernandes, quando apresenta uma leitura de capitalismo dependente, ajuda nessa desconstrução, instituindo uma leitura relacional do desenvolvimento, levando em consideração as articulações entre os países periféricos e os países desenvolvidos. Dessa forma, diferentes categorizações de países, ao longo do tempo, incluindo a atual divisão entre países desenvolvidos, subdesenvolvidos e em desenvolvimento, pouco contribuem para entendermos o que de fato é a divisão internacional do trabalho e o caráter associado entre as economias nacionais, através de suas burguesias.

E para pensarmos sobre a constituição de um desenvolvimento dependente das relações capitalistas em países como o Brasil, é fundamental buscar no movimento da história a formação territorial na qual estamos inseridos. Nesse sentido, toda a discussão colocada por Caio Prado Júnior é fundamental. Sua análise sobre o perfil de economia 
colonial que caracteriza o Brasil, com reflexos até os dias atuais, auxilia para que possamos entender as várias armadilhas do desenvolvimento capitalista em nosso percurso histórico. Como discutimos, aquilo que é colocado por esse autor pode ser reconhecido como um passivo colonial, logo como um passado-presente na formação do Estado nacional não só no Brasil, como em toda a América Latina. Compreendemos que essa interpretação não se revela como uma leitura démodé do autor, que não mais corresponde com a realidade atual. Muito pelo contrário, o passivo colonial discutido por Caio Prado Júnior atravessa a formação territorial do Brasil e se desvela na própria constituição de facetas da burguesia fincadas no atraso, no latifúndio, no trabalho escravo.

Como indicamos ao final do item anterior, reconhecemos a importância conceitual do debate a partir de uma leitura que considera o desenvolvimento enquanto desigual e combinado. Nesse sentido, Florestan Fernandes apresenta um refino intelectual sine qua non para entendermos o que é a relação entre o arcaico e o moderno na conformação do regime de classes e do modelo societal de país periférico. Contudo, vale a pena ressaltar que o debate sobre a natureza combinada do desenvolvimento também já aparece anos antes na obra Celso Furtado, embora com menor frequência do que na obra de Florestan Fernandes.

Outra importante contribuição que podemos elencar desses autores é o desafio de pensar a realidade nacional não descolada das dinâmicas globais. Eles nem fizeram coro à necessidade de entender o nosso desenvolvimento como autoexplicativo somente a partir de fatores endógenos da economia nacional, nem compuseram o discurso da determinação do externo frente ao interno. Assim, instituíram uma importante agenda de pesquisa sobre a formação territorial, sociológica e econômica do Brasil, mas sempre partindo de como essas dinâmicas dialogavam historicamente com a divisão internacional do trabalho e com as reconfigurações da dinâmica do capital nos centros hegemônicos. Celso Furtado, por exemplo, apresenta uma leitura para o (sub)desenvolvimento no Brasil a partir da relação desse país com outros processos de desenvolvimento que ocorrem nos países europeus ocidentais. Por sua vez, Florestan Fernandes investiga os desdobramentos da transição da sociedade colonial para a sociedade nacional no Brasil 
imperial considerando as dinâmicas políticas e econômicas em uma articulação que contempla os planos nacional e internacional.

Assim, queremos finalizar este texto falando sobre legado. Mais do que conceitos fundamentais para a análise da realidade brasileira, compreendemos que Caio Prado Júnior, Celso Furtado e Florestan Fernandes são responsáveis por constituir um legado para o pensamento crítico brasileiro, latino-americano, universal. Em diferentes áreas das ciências humanas e sociais, tais como a história, a economia, a geografia, a sociologia etc., o legado deixado por esses autores nos desafia a avançar numa leitura desveladora do Brasil sem cair em armadilhas pragmáticas e/ou idealistas. A necessidade de pensarmos o desenvolvimento das relações capitalistas de modo geral, mas no Brasil em particular, exige de nós a centralidade de reler esses três intelectuais. Não como num retrovisor que diagnostica um pretérito ultrapassado, mas como uma ponte que nos aproxima de uma leitura de totalidade concreta do presente, mediada pelas condições espaço-temporais que nos atravessam.

\section{Referências}

EVANS, Peter. A tríplice aliança: as multinacionais, as estatais e o capital nacional no desenvolvimento dependente brasileiro. Rio de Janeiro: Zahar, 1980.

FERNANDES, Florestan. A sociologia no Brasil: contribuição para o estudo de sua formação e desenvolvimento. 2. ed. Petrópolis, RJ: Vozes, 1980.

FERNANDES, Florestan. Em busca do socialismo: últimos escritos \& outros textos. São Paulo: Xamã, 1995.

FERNANDES, Florestan. A revolução burguesa no Brasil: ensaio de interpretação sociológica. 5 ed. São Paulo: Globo, 2006.

FERNANDES, Florestan. Sociedade de classes e subdesenvolvimento. 5 ed. rev. São Paulo: Global, 2008.

FURTADO, Celso. Desenvolvimento e subdesenvolvimento. Rio de Janeiro: Fundo de Cultura, 1961. 
FURTADO, Celso. O mito do desenvolvimento econômico. Rio de Janeiro: Paz e Terra, 1974.

PRADO JÚNIOR, Caio. História econômica do Brasil. 17. ed. São Paulo: Brasiliense, 1974.

PRADO JÚNIOR, Caio. História e desenvolvimento. 3. ed. São Paulo: Brasiliense, 1989.

Recebido em: 16/10/2019 Aprovado em: 09/06/2020

Universidade do Estado de Santa Catarina - UDESC Centro de Ciências Humanas e da Educação - FAED

Revista PerCursos

Volume 21 - Número 46 - Ano 2020 revistapercursos@gmail.com 